\title{
PROGRAMA DE INTEGRAÇÃO COMUNITÁRIA: EM BUSCA DE NOVAS ESTRATÉGIAS E NOVOS SENTIDOS À VIDA
}

\author{
Pedro Fredemir Palha* \\ Gislaine Messias de Lima** \\ Iranilde José Messias Mendes***
}

PALHA, P.F.; LIMA, G.M.de; MENDES, I.J.M. Programa de integração comunitária: em busca de novas estratégias e novos sentidos à vida. Rev.latino-am.enfermagem, Ribeirão Preto, v. 8, n. 2, p. 5-10, abril 2000.

\section{Todo político, todo o artista, todo cidadão deveria saber que, independente da ocupação que escolheu na vida, a própria vida só existe porque existe movimento.}

Twyla Tharp.

O Programa de Integração Comunitária da Secretaria Municipal de Saúde de Ribeirão Preto, objetiva à Promoção da Saúde, direcionando suas ações na mudança do estilo de vida. O objetivo desse trabalho é olhar à luz do conceito ampliado de Promoção da Saúde e com a leitura de depoimentos de uma parcela usuária do programa, como ele tem se constituído como uma estratégia no aumento da autonomia e emancipação da população. A análise revela que o programa vem potencializando a autonomia e emancipação da população, e colocando-se enquanto um instrumento importante na defesa da vida.

UNITERMOS: serviços de saúde, promoção da saúde, politica de saúde

\section{APRESENTAÇÃO}

Esse trabalho tem como finalidade uma discussão teórico-conceitual do Programa de Integração Comunitária - PIC -, idealizado por uma pesquisadora da Escola de Enfermagem de Ribeirão Preto, Universidade de São Paulo - EERP/USP -, tendo como instituições envolvidas além da EERP-USP, a Secretaria Municipal de Saúde de Ribeirão Preto - SMSRP - e o Centro de Educação Física Esportes e Recreação do Campi Ribeirão Preto - CEFER/USP.

Ciente estamos de que as discussões que trazemos aqui, é neste momento, mais inquietações do que propriamente definições acabadas, mas constitui-se como um momento pertinente para o delineamento investigatório que estamos iniciando.

É mister considerar que o presente programa tem suas ações voltadas à Promoção da Saúde, com o direcionamento da suas ações na mudança do estilo de vida, e nesse sentido, gostaríamos de estar esclarecendo que, do ponto de vista da organização das práticas sanitárias, o enfoque na mudança do estilo de vida tem sido alvo de críticas quando propõe-se em onipotência pensar ser a grande saída para a resolução dos problemas de saúde da população, crítica da qual concordamos plenamente.

No entanto, a abordagem que procuraremos enfocar tem um outro caminho, o de que, esse programa com suas especificidades pode ser um parceiro importante ao pensarmos a saúde como um bem público, pois acreditamos que a incorporação de práticas de saúde que buscam aumentar o coeficiente de autonomia e emancipação das pessoas não podem ser desconsideradas.

Para tanto, também buscamos as bases fundantes

\footnotetext{
* Professor Assistente do Departamento Materno-Infantil e Saúde Pública da Escola de Enfermagem de Ribeirão Preto da Universidade de São Paulo. Doutorando do Programa Interunidades em Enfermagem da Escola de Enfermagem de Ribeirão Preto/Escola de Enfermagem da Universidade de São Paulo.

** Mestranda do Curso de Pós Graduação em Enfermagem em Saúde Pública do Departamento Materno Infantil e Saúde Pública da Escola de Enfermagem de Ribeirão Preto da Universidade de São Paulo

*** Professor Associado do Curso de Pós Graduação Mestrado-Doutorado da Escola de Enfermagem de Ribeirão Preto da Universidade de São Paulo e Professor Visitante da Faculdade de Medicina do Triângulo Mineiro no Departamento de Enfermagem em Educação e Saúde Comunitária do Curso de Graduação em Enfermagem
} 
da organização desse programa, que embora esteja incorporado como um programa da SMSRP, parece caminhar paralelo a ela, se não, poderíamos até arriscar afirmar de que, é um dos programas que menos tem sido olhado por parte dos gestores e técnicos da área da saúde, e que independente disso, cotidianamente cresce a adesão da população à ele.

Nesse sentido, no decorrer do trabalho aparecerão questionamentos, decorrentes das leituras efetuadas sobre a temática, e pelo acompanhamento do PIC na qualidade de observadores, que tem nos intrigado a pensar em uma série de relações que aparecem no programa e que fogem a própria diretriz inicial deste.

\section{APROXIMAÇÃO AO TEMA}

O PIC surgiu em novembro de 1993 em caráter experimental em uma Unidade Básica de Saúde -UBS da Vila Tibério com 10 participantes, esses inicialmente foram encaminhados por técnicos da saúde, e tinham como características comuns queixas em relação a dores articulares e uso com relativa freqüência de terapêutica antiinflamatória e analgésica.

Tem em seus objetivos ampliar o papel das Unidades Básicas de Saúde -UBS's- através da prática de exercício físico, recreação, e fomentar a participação da população na UBS, como meio de torná-la um local onde trabalhadores e comunidade possam se transformar, apontando para o auto cuidado, responsabilidade pela saúde individual e sócio ecológica (MENDES, 1996).

Visa atingir a população acima de 18 anos de idade, supostamente sadios e/ou portadores de doenças crônico degenerativas e expostos a riscos, registrados ou não nas UBS's. É também proposto a partir das inquietações da pesquisadora como docente da disciplina Saúde do Adulto no sentido de adequar o ensino, pesquisa e extensão de serviços à visão inovadora de saúde pública.

O PIC, segundo MENDES (1996), tem como eixo norteador as orientações emanadas da Carta de Ottawa (WHO, 1986), um dos mais significativos documentos já produzidos que aponta a educação para a saúde e as políticas públicas como elementos fundamentais no conceito de Promoção da Saúde.

Esse documento apregoa a necessidade de dirigir a atenção à práticas de saúde que levem as comunidades a desenvolverem hábitos de vida de modo a ampliarem o seu grau de resistência a determinadas morbidades. Também orienta que a organização dos serviços devem estar voltados ao atendimento das comunidades utilizando estratégias e ações coordenadas na busca e elaboração de políticas públicas mais saudáveis.

Caminhando nesse sentido, MENDES (1996), comenta em seus estudos que a estratégia de Promoção de Saúde é em seu sentido amplo, um elo mediador entre as pessoas e o meio, primando em determinados momentos a escolha pessoal com responsabilidade social. Assim, diz a autora, transita através de duas vertentes complementares, a educação para a saúde e as políticas sociais, dois eixos capazes de fazer um movimento de ações integradas e interativas por meio de instrumentos políticos, legislativos, fiscais e administrativos, onde o conceito de saúde é apreendido como resultante do modo de vida das pessoas e da sua interação com o meio físico e social.

Ainda, segundo o pensamento da autora, o caminhar para a Promoção da Saúde tem uma relação direta com o desenvolvimento do grau de autonomia das pessoas. No sentido de que elas possam gerir o cuidado pela própria saúde, bem como, exercer o controle dos determinantes sobre a mesma. Isto, de certa forma, apresenta-se como um desafio ao atual modelo de organização da assistência à saúde, que parece não agregar efetivamente a população nas instâncias de programação, planejamento, avaliação e, controle dos serviços.

Reforça MENDES (1996), que uma outra finalidade do PIC é estimular as UBS's a ampliar o seu papel social incorporando outras atividades como a prática de exercícios físicos, lazer, recreação, informações sobre saúde holística e a efetiva participação da comunidade.

A ampliação do papel social das UBS's na perspectiva da autora é torná-la um local onde os trabalhadores de saúde e comunidade possam transformar-se em atores políticos, onde o auto-cuidado e a responsabilidade pela saúde individual e sócioecológica, sejam um estímulo ao exercício compartilhado, permeado por vínculos de compromisso e solidariedade. Essas características segundo a autora, têm conferido ao PIC uma proposta inovadora para a saúde (MENDES, 1996).

O PIC nesse sentido, parece ser um programa que virá contribuir para o movimento de cidades saudáveis que aparece no início dos anos $70 \mathrm{em}$ Toronto no Canadá, e depois ganha amplitude com a criação do projeto Health Cities pelo Escritório Europeu da Organização Mundial da Saúde (WHO, 1986), e apresenta como finalidade a estratégia de saúde para todos no nível local. Conferindo maior autonomia política e administrativa às cidades pautada na sua essência pelo conceito de Promoção à Saúde. Dessa forma, fixa quatro objetivos que devem ser eixos norteadores das políticas públicas: visibilidade para a saúde, mobilização e decisão política, mudança institucional e ação inovadora para a saúde, linha na qual a autora tem pautado as ações desenvolvidas pelo PIC.

Assim, preconiza a OMS para a sua efetivação, a intersetorialidade através de setores como o esporte, 
bem-estar, saúde, planejamento e serviços privados, bem como, clubes, salões e outros. Portanto, a programação contempla um conjunto de serviços públicos e privados como indispensáveis à condição do estado de bem-estar do indivíduo e da comunidade.

Essa estratégia de Município Saudável, que busca ações plenas para o indivíduo e coletividade no âmbito local, é na verdade uma proposta de renovação conceitual, metodológica e de práticas de saúde. Proposta essa que ganhou amplitude durante a Conferência Internacional sobre Promoção da Saúde realizada pela Organização Mundial da Saúde no Canadá (WHO, 1986).

Assim, de acordo com CARVALHO (1996), o conceito de Promoção da Saúde, resultante desse evento constituiu-se em um marco conceitual fundamental na área de saúde pública, um balisador das políticas e estratégias. Desse modo, a Carta de Ottawa, configura uma inovação à própria Conferência de ALMA-ATA em 1977, na qual a imagem objetivo propunha Saúde para todos no ano 2000, através da expansão da atenção primária às populações.

Em suas intenções, a Carta de Ottawa diz que Promoção da saúde é o nome dado ao processo de capacitação da comunidade para atuar na melhoria de sua qualidade de vida e saúde, incluindo uma maior participação no controle deste processo. Enfatiza também o fato de que a plena condição de bem-estar depende de indivíduos que identifiquem as suas aspirações, buscando satisfazer as próprias necessidades, modificando favoravelmente, na medida do possível, o seu meio ambiente. Nesse sentido, a Carta de Ottawa

(...) reconhece, então, que as decisões políticas de outros setores tem uma contribuição crucial para a saúde; e que os ambientes físicos e sociais são importantes para o estabelecimento das condições de saúde e como parâmetros para o comportamento sanitário; que a comunidade pode e deve desempenhar um papel fundamental nas ações sanitárias; e que os serviços de saúde precisam ser reorientados (CARVALHO, 1996, p.117).

Assim, a saúde passa a ser entendida como um recurso para a vida e não apenas um objetivo para viver. E deve ser percebida como o maior recurso para o desenvolvimento social, econômico e pessoal, dimensionando-o como um fator importante na qualidade de vida.

A conquista desse recurso depende do sucesso da capacitação dos indivíduos em conduzir a sua saúde, através do conhecimento dos fatores possíveis de serem controlados pelos próprios homens. Para tanto, é mister enfatizar a necessidade do uso de capacidades sociais, pessoais e físicas. Pois assim, a Promoção da Saúde deixa então de ser responsabilidade exclusiva do setor saúde, e anda para além de um estilo de vida saudável, na busca contínua da autonomia do homem.

Nesse sentido, temos encontrado diferentes correntes do pensamento teórico na área de saúde, que tem envidado esforços na constituição de um novo paradigma sanitário, apresentando propostas e experiências, e reflexões de modelos alternativos que ao nosso tempo mostram diversidades, convergências e complementaridade.

Essas correntes tem discutido a necessidade de transformações profundas no campo da assistência, serviços, instituições, profissionais de saúde, e nas relações com a comunidade. Dentre eles podemos citar os estudos de CAMPOS (1994); MENDES (1995); TESTA (1995); CARVALHO (1996); MENDES (1996) e STROZZI (1997), que defendem a ampliação da autonomia do indivíduo e da comunidade como uma das possibilidades de reconstrução do conceito de cura, a partir da leitura do seu corpo, da sua doença, das suas relações com o meio social e, ampliar as suas possibilidades de sobrevivência e de qualidade de vida.

E nesse caminho da autonomia dois fatores são apontados por MENDES (1996), como fundamentais no PIC: a informação e a relação de sujeitos entre técnicos e comunidade.

Com relação à informação, segundo a autora é oferecido um curso na perspectiva holística de saúde. Este curso instiga a relação do homem com o meio natural e social, e tem como um dos objetivos o auto-cuidado e a responsabilidade pela saúde individual e sócio-ecológica. Quanto a relação de sujeitos, esta dar-se-ia de forma horizontal, de respeito mútuo e reconhecendo-se como cidadãos.

O conteúdo do Programa segundo MENDES (1996), é apresentado de tal modo que os participantes percebam a possibilidade de transformação de acordo com a participação da população, e que a saúde é um bem, que depende do esforço individual e coletivo.

Em decorrência do entrosamento e criatividade dos participantes relata a autora, outras atividades são realizadas, tais como: participação em coral, passeios, esportes, festas, gincanas, olimpíadas, festivais de danças, atividades culturais em geral. Estas atividades, segundo ela, têm potencializado de fato a criatividade, espontaneidade e expressividade dos participantes.

Nesse sentido, Freire discute que o conhecimento original de cada ser humano é único em relação aos outros homens. Dizendo que podemos representá-lo através de uma equação aritmética: o comum a todos os homens em denominador, e original em numerador (FREIRE \& BRITO, 1988, p.47).

Essa equação segundo ele, revela o potencial de cada pessoa. Quando o homem utiliza-se da criatividade, 
da crítica, da originalidade e do conhecimento, o que ele vai produzir é algo muito imprevisível, que no entanto, tem um valor imenso do ponto de vista da satisfação pessoal. Do denominador ele vai extrair os meios considerados não criativos, mas que são fundamentais ao convívio e solidariedade social.

Isso nos faz pensar que da forma como os serviços de saúde são organizados hoje, com exceção à algumas experiências, pouco tem permitido aflorar nos homens a espontaneidade e a originalidade, pois, a lógica que tem permeado a assistência é pautada pelo atendimento ao sofrimento, e na pouca resolutividade dos problemas.

O resgate desse homem no numerador, pelo PIC, aparece a partir de algumas experiências cotidianas vivenciadas no programa, como é relatado por uma das participantes do programa, que tem revelado seu lado de poetisa após perceber esse programa como um espaço potencializador para a expressão, criatividade e a arte. E que, segundo seu depoimento, seu lado poético por anos a fio permaneceu guardado nas gavetas em sua casa.

Outros depoimentos**** relatam que a adesão ao programa não foi apenas por encaminhamento dos técnicos de saúde, mas porque ficaram sabendo através de algumas amigas. E que, até então, eram pessoas com poucas amizades que ficavam em casa sozinhas pensando em doenças e até na morte. Outro aspecto importante relatado foi o fato de que o consumo de antinflamatórios e tranqüilizantes foi reduzido ou mesmo suspenso.

Ao contrário, outros depoimentos, apontam indignação com relação a um determinado bairro onde o PIC teve retrocesso, e dizem que a estagnação do programa deve-se as relações com interesses políticos por parte de algumas pessoas.

A autonomia da comunidade parece estar se constituindo num dos eixos mais importantes do PIC, pois, como é apontado por MENDES (1996), hoje existem PIC's que não foram implantados pela SMSRP enquanto um programa, mas frutos da organização das próprias comunidades locais, e mais, alguns, os mais antigos, tendem a caminhar sozinhos através da criação de uma associação para a manutenção dos instrutores***** de educação física.

Situação que nos leva a pensar que, a transformação do sujeito parece caminhar para um impulso natural e espontâneo, e dependendo da forma, pode adquirir uma adaptação às teorias já aceitas e acabadas, ditas como verdades absolutas, ou ser um espaço de leitura do meio, onde o cotidiano cede espaço a mudança.

Partindo disso, parece que o PIC adotou uma estratégia não convencional de divulgação do conhecimento e de estímulo à mudança nos aspectos referentes ao estilo de vida, porém como já falamos tem influenciado e despertado sobremaneira conhecimentos da subjetividade humana que pareciam estar adormecidos. Nesse sentido, não estaria o PIC contribuindo no processo emancipatório e no resgate da cidadania das pessoas? Questão que não se esgota neste momento, mas que será objeto de maior investigação posteriormente.

Essa estratégia parece que tem levado os sujeitos a decodificarem suas próprias mensagens percebidas de dentro e fora deles, e assim entendemos que, esse é um exercício de sabedoria e que nasce essencialmente da praxis.

Concordamos com FREIRE \& BRITO (1988), quando diz que conhecer, é sem dúvida nenhuma, a descoberta de si mesmo, no ato de viver e de se relacionar com o seu corpo, sua identidade, e para além disso, conviver com a natureza social do homem: ser os outros, através da comunicação e da união.

E nos parece oportuno lembrar que, concordamos com muitos autores quando afirmam que o setor saúde, por si só, não detém condições de controlar a diversidade de variáveis que envolve a saúde, necessitando de uma ação coordenada intersetorial e interdisciplinar respeitando a especificidade dos grupos populacionais.

Neste sentido, a política de Promoção da Saúde, requer além da identificação e remoção de obstáculos, uma parceria e um compromisso político entre os vários setores sociais ligados ou não a saúde, objetivando a adoção de políticas públicas que sejam mais saudáveis.

Segundo a Carta de Ottawa (WHO, 1986), a saúde é construída pelo cuidado individual e coletivo, pela capacidade de autonomia, ou seja, pela tomada de decisão e controle sobre as circunstâncias da própria vida e na maximização de esforços coletivos na obtenção da saúde a todos, e que para isso, nas diversas fases do planejamento, implementação e avaliação das atividades de promoção da saúde deve haver participação e coresponsabilidade de todos os setores envolvidos no processo, assim como a própria comunidade.

Portanto, pensar em Promoção da Saúde é estar

\footnotetext{
**** Depoimentos coletados no $2^{\circ}$ semestre de 1998 por alunos da disciplina ERM-234 - Saúde do Adulto da Escola de Enfermagem de Ribeirão Preto, junto a população freqüentadora do PIC com o intuito de vivenciar experiências promocionais e práticas alternativas à saúde

***** Segundo informações do coordenador, convidado da disciplina ERM-234 - Saúde do Adulto da Escola de Enfermagem de Ribeirão Preto, dos 12 instrutores de educação física que acompanham os PIC no desenvolvimento das suas atividades apenas 1 é mantido pela SMSRP, 2 pela Secretaria Municipal de Esportes, 1 pela Universidade de Ribeirão Preto - UNAERP, e 8 são mantidos através do Convênio Escola Empresa - CIEE
} 
sensibilizado para que a saúde seja entendida no seu conceito mais amplo, ou seja, circunstanciada pela redução da violência, habitação digna, ensino de qualidade, política alimentar, política de geração de empregos, manutenção de um ecossistema saudável e natural, atendimento ao homem nas suas complexidades e especificidades no que tange à saúde, justiça social e equidade.

Segundo STROZZI (1997), a forma mais visível de perceber a iniqüidade nas sociedades Latinoamericanas, é observando o local onde o indivíduo e coletividade reside, instância onde é possível também identificar seu estilo de vida.

Convergindo na mesma linha de pensamento sobre o município como espaço potencializador que permite a identificação e resolução de problemas, Mendes aponta que o princípio da adstrição permite a objetiva responsabilidade política, jurídica, administrativa e técnica dos serviços de saúde e das autoridades locais ante a população que nasce, vive, adoece e morre naquele espaço (MENDES, 1995, p.150).

Desta forma, entendemos que o enquadramento dos municípios em territórios parece ser um dos instrumentos que permite observar os determinantes e os agravos à saúde dentre os vários cenários que compõe uma população municipal, assim como, parece influenciar no maior ou menor grau de solidariedade dentro da própria comunidade, onde os pares identificam-se.

Nesse sentido, CAMPOS (1991), aborda que o uso dessa diretriz traria não só benefícios para a prática clínica, como estimularia o combate a terapêutica excessiva na medida em que proporia novos campos terapêuticos, mais ligados ao psíquico, a reeducação sanitária, instituindo dessa forma novas avaliações das práticas de saúde. Essa abordagem é um desafio para a prática profissional, pois exigirá um novo olhar, uma visão mais holística de caso a caso, superando paulatinamente o mecanicismo biologicista e reducionista que tem sustentado a prática da clínica, e a organização dos serviços.

Concordamos plenamente com o autor, quando fala que a transformação da atenção à saúde não pressupõe rompimento ou desligamento do apoio da clínica, mas refere-se a necessidade de ampliação dessa prática. No sentido de que os indivíduos tenham relações mais maduras com a doença, com a prevenção, com os técnicos da saúde, com os dispositivos tecnológicos, com as instituições de saúde e com seus pares na comunidade. E que esse seja, em sua ação norteadora um processo de aflorar nos indivíduos bases que podem potencializar a autonomia e emancipação.

É o caminho, segundo CAMPOS (1994), para chegar as estratégias de temas como vínculo, acolhimento, contrato, auto-cuidado, responsabilização, dentre outros, que levam ao exercício moderno da clínica e da cidadania, para ele a Saúde Pública enfrenta hoje profundos desafios pois

$\mathrm{Na}$ realidade perdemos a capacidade de combinar, com liberdade, uma série de tecnologias conforme o problema a ser enfrentado, de maneira a aliviar e diminuir as agruras do social e do econômico sobre a vida e morte das pessoas. Repensar a Saúde Pública hoje exige heterodoxia metodológica.(...) Ousar pensar uma Saúde Pública ativa, que procure a comunidade, que instigue e descubra processos mórbidos; mas que seja também capaz de criar meios de incorporar cidadãos, com toda sua subjetividade e preconceitos, em programas onde esta dimensão é essencial (...) (CAMPOS, 1994, p.57).

A Saúde Pública não pode omitir-se a essa realidade e necessita partir para ações mais amplas, mais humanas e que incorpore na construção de políticas sociais a interdisciplinariedade como meio de retotalizar a cisão que orienta o atual modelo de saúde. A retotalização é entendida aqui como a construção da totalidade do real.

Portanto, as ações de saúde devem basear-se na inter-relação dos sujeitos históricos a partir do diálogo e da apreensão do senso comum como mecanismo de reflexão, e os profissionais da área de saúde também necessitam revitalizar o potencial crítico que dá sustentação teórica à reconstrução do conhecimento que determina as ações.

Essa aproximação do senso comum, do diálogo e da revitalização, facilita o ato de conquistar o conhecimento, para juntos, comunidade e técnicos, debruçarem-se criticamente sobre a realidade do cotidiano, e finalmente desenvolver um trabalho humano mais competente e que leve a considerar os sujeitos a maximizar sua autonomia e cidadania.

\section{CONSIDERAÇÕES FINAIS}

Neste contexto buscamos refletir sobre a experiência do PIC, já que testemunhamos a sua impressionante ampliação, pois hoje faz parte de 30 UBS's e tem mais de 2000 pessoas participando em suas atividades.

Essa vivência tem nos mostrado que, embora reconheçamos que seu eixo seja na mudança do estilo de vida, não o torna descartável como processo, pois traz um potencial para incorporação de alternativas metodológicas que tem estimulado o potencial dos sujeitos em sua autonomia e na defesa da vida. E nesse 
sentido, parece que esses sujeitos buscam, através das ações cotidianas desenvolvidas pelo PIC, o fluxo existencial fundamentado no sentido de interioridade, auto-estima, e solidariedade nas relações sujeito-mundo, uma relação que parece estar contribuindo na emancipação e no alargamento da cidadania dessa parcela da população que freqüenta o programa, uma experiência que nós, técnicos, precisamos reaprender.

\section{PROGRAM OF COMMUNITY INTEGRATION: IN THE SEARCH FOR NEW STRATEGIES AND NEW WAYS OF LIFE}

The Program of Community Integration of the Municipal Bureau of Health of the city of Ribeirão Preto aims at promoting health, directing its actions for the change of life styles. The purpose of this study is to look, in the light of the framework of Health Promotion and through declarations of users of the program, how it has been formed as an important strategy to increase the autonomy and emancipation of the population. The analysis reveals that the program has improved the autonomy and emancipation of the population, as an important instrument for life defence.

KEY WORDS: health services, health promotion, health policies

\section{PROGRAMA DE INTEGRACIÓN COMUNITARIA: EN BUSCA DE NUEVAS ESTRATEGÍAS Y NUEVOS SENTIDOS DE LA VIDA}

El programa de Integración Comunitaria de la Secretaría Municipal de Salud de Ribeirão Preto tiene como objetivo la Promoción de la Salud, orientando sus acciones hacia el cambio en los estilos de vida. El objetivo de ese trabajo es mirar, a luz del referencial teórico ampliado del concepto de Promoción de la Salud y con la lectura de declaraciones de una parte de usuarios del programa, como él se ha constituido como una estrategia importante en el aumento del coeficiente de autonomía y emancipación de la población. El análisis revela que el programa viene fortaleciendo la autonomía y emancipación de la población, colocándose como un instrumento importante en la defensa de la vida.

TÉRMINOS CLAVES: servicios de salud, promoción de la salud, politicas de salud

\section{REFERÊNCIAS BIBLIOGRÁFICAS}

\section{CAMPOS, G.W.S. A saúde pública e a defesa da} vida. São Paulo: Hucitec, 1991.175 p.

02. CAMPOS, G.W.S. Considerações sobre a arte e a ciência da mudança: revolução das coisas e reforma das pessoas. O caso da saúde. In: CECÍLIO, L.C. de O. Inventando a mudança na saúde. São Paulo: Hucitec, 1994. Cap. 1, p. 29-87.

03. CARVALHO, A.I. Da saúde pública às políticas saudáveis. Ciência \& Saúde Coletiva, Rio de Janeiro, v.1, n.1, p.104-121, 1996.

04. FREIRE, R.; BRITO, F. Utopia e paixão: a política do cotidiano. 8. ed. Rio de Janeiro: Rocco, 1988. $109 \mathrm{p}$.
05. MENDES, E.V. (org.) Distrito sanitário. O processo social de mudança das práticas sanitárias do Sistema Único de Saúde. São Paulo: Hucitec, 1995. 310p.

06. MENDES, I.J.M. Promoção de saúde: caminhando para o único. Ribeirão Preto, 1996. 148p. Tese (Livre Docência) - Escola de Enfermagem de Ribeirão Preto, Universidade de São Paulo.

07. StrozZI, J.B. Sus pense: uma reflexão epidemiológica sobre o sus e outras aplicações acadêmicas. Paraná: Hucitec, 1997.194p.

08. TESTA, M. Pensamento estratégico e lógica de programação. O caso da saúde. São Paulo: Hucitec, 1995. 306 p.

09. WORLD HEALTH ASSOCIATION. Ottawa charter for health promotion.In: AN INTERNATIONAL CONFERENCE ON HEALTH PROMOTION. Ottawa,1986. 